\title{
Tension and urban sustainability: case study - the metropolis of Mashhad, Iran
}

\author{
E. S. Mashhadi ${ }^{1}$ \& J.-F. Lejeune ${ }^{2}$ \\ ${ }^{1}$ University of Miami School of Architecture, USA \\ ${ }^{2}$ University of Miami, USA
}

\begin{abstract}
The flawed transformation of many old cities in response to contemporary emerging conditions has created incongruities which have drastically reduced their initial sustainable performance. There are examples however, where the inevitable and necessary transitions have adopted the promising qualities of traditional typologies and urban morphologies. From the very beginning, Mashhad - Iran's second most populous metropolis - has developed a unique character. Not confined to Islamic, semi-medieval urban morphology neither to axial or purely gridded configuration, it has sustained a symbiotic equilibrium between two opposing systems. Purported to be a religious city, the other aspect has never been clearly discussed. Indeed, while the hegemony of religious ideology has never allowed the annunciation of the city's liberal interests, its overall configuration and civic character has been the expression of tension between two contrasting themes.

A sacred event established a thriving center. The locus of all religious views generated a complex centripetal and radial configuration. The contest to remain as close as possible to the center, has resulted in a congested and irregular fabric. The axis, on the contrary, disassociated from the former theme, provides movements outward and evokes a mental and physical freedom which yields to linear and gridded patterns. The inclination toward a liberated expansion has been conducive to the formation of ample open and green spaces, scattered throughout the city. Hence, the dichotomy of two doctrines has been reflected into their urban manifestations. Their correspondence and simultaneity in time and space have been the underlying principle for the city's fascinating status. By analysing the key historical moments in the evolution of the city, this paper will describe how urban morphology, its corresponding socio-cultural structure and their mutual influence on the city's ecology, have collectively contributed to the formation of a sustainable metropolis.
\end{abstract}

Keywords: urban sustainability, morphology, urban typology, Mashhad, metropolis, religious city, urban axis, sustainability, urban design, Iran. 


\section{Introduction: reversed sustainability - cross-fertilization of incompatible forces}

Although in many cases urban sustainability as a design concept is associated with a preconceived ideal destiny of an urban settlement, older cities, for the most part do not subscribe to this desire. The notion of a sustainable city might be reminiscent of the mannerist architect's quest for an ideal city. The new ideal however, is not simply the Filarete's figural and compositional one, nor St. Thomas More's Utopia, but rather a comprehensive and multifaceted notion toward sustainable dwelling - an ultimate symbiosis. This Hyper-Ideal aspires for the synthesis of all: Renaissance figural ideal, modern social ideal, postmodern plural and perhaps economic ideal and the most recent, environmental ideal.

While harmonious juxtaposition of social, economic and environmental components culminate in an ideal sustainable condition, surprisingly Mashhad has developed its sustained character not out of harmony but within an inherited tension and indeterminacy. This sustainability has not been established out of ideal components but from the balanced equilibrium of opposing forces. Mashhad is at the same time a deviation from - and ironically, a proof of Derrida’s “classical philosophical opposition”, which argues that it will never be possible to have the peaceful coexistence of two opposing notions; instead a "violent hierarchy" through which one pole will prevail the other [1]. The paper will demonstrate how the approximation, syntax, simultaneity and balance between all seemingly competing forces have contributed to the city's urban sustainability.

What gives the city a degree of consistency and sustainability is the smooth fluctuation between incompatible themes. Mashhad, all along its history has been the theater of unruffled transitions and transformations. Since there has been an underlying hesitation, since every single move, right or left, has been approximated in relation to its counterpoint, any urban intervention has been realized with a great deal of consideration. Thus nothing has been conceived with haste. By discussing the mechanisms and urban manifestations through which a symbiosis between Shi'a and Sunni, between religious and nonreligious, between center and axis, between the shrine and the new city, has been substantiated, this paper will theorize the reversed sustainability.

\section{Myth and equivocated origin}

Starting from an event - the martyrdom of Imam Reza - and not from a wellhabitable place, the city has an inherited paradox between myth and reality, between a physical existence and a memory.

The holy shrine, immersed in her glory and splendor, hosting incessant surge of her avid and ardent devotees, huddled together, captivating them by her glittering golden dome, welcoming them in a series of porticos and courtyards. The city was there because of her. She gifts them, with her exquisite beauty and 
infallible grace an image - an image of spiritual prosperity, salvation, stability and security. Pilgrims endow her, their most precious assets, land, gold and money. While her glistening dome redefines the azure sky, her highly ornamented and sublime interior fascinates the eye, so there will remain no hesitation to imagine anything but her truthfulness and honesty. Her captivating mirrors and tile works evade any reference to anywhere but to heaven; yet, she suffers deep inside. For centuries with her might and representational vigor, she was trying to eclipse a pervasive, but shaded reality. She remembers that her existence was not the reification of unanimous sincerity, devotion and adoration, but ambivalence, contention and betrayal.

The Ommayid's governor of Khorasan province, H. Qahtabah, built himself a great garden and within the garden, a palace between the villages of Noghan and Sanabad. Later during the 8th century, a commander, Harun, was buried inside the palace and upon his tomb a shrine was built. Maamon, the Harun's successor after some years of his monarchy, due to the revolt which was going on against him in Iraq, found his sovereignty at risk. Therefore he nominated the Imam Reza as his crown prince to achieve the Shiiet support. After a year, Imam Reza launched a trip to Baghdad, arriving at Noghan he entered the Sanabad governor's palace, was poisoned and died after three days. "The Shi'a faithful claimed that the Abbasid caliph, al-Mamun, ordered the poisoning of Imam Reza, who was thus martyred” [2]. Imam was buried next to Harun, the Abbasid caliph. Around this ambivalent nucleus, the city of Mashhad was shaped.

\subsection{The city's myth and muted cry}

The struggle between myth and reality, between opposing forces, between competing domains and between the palace's centripetal organization and the linear configuration of garden's axis, have remained in the city's urban character, yet the myth and the dichotomy were never openly divulged. The hegemony of Islamic ideologies perhaps originated far before Mashhad being originated. Kia argues that, "the Arab invasion of Iran in the seventh century AD had marked the beginning of a new era of foreign domination, cultural barbarism, political despotism, and religious fanaticism” [3].

Although Mashhad emerged from a religious event, it did not found its particular status until the Safavid period at the beginning of $16^{\text {th }}$ century, when the official practice of Shi'ite Islam became instrumental in shaping national identity and supporting political ascendency [4]. By declaring the Shi'ism as the official religion, Shah 'Abbas Safavid suppressed and ignored Iran's multicolored cultural and religious carpet. From this point on, religious discrimination institutionalized and continued to extend to the present.

Despite all attempts to postulate Mashhad as an absolute symbol of Shi'a and wrap its pluralistic nature under a single designation, the city never fully surrendered to the religious hegemony. Whenever the imposed suppression loosened, or tremendous financial propaganda plummeted, the pluralistic and liberal interests emerged; Arg Street, built during Pahlavi II dynasty, having bars, dancing and other leisure activities is one example [5]. The same imposed wrapping, which has veiled the true look of Iran's female population, has 
masqueraded the ambiguous nature of the shrine as well. The former, shades the beauty and fetters their prerogative freedom, the latter provides a falsified image and stifles the underlying realities. "The reform program launched by Reza Khan in 1925 demanded that Iranian women, shed their veil” [6, p. 225]. The shrine's dominance was also questioned and the clergies' authority plummeted [6, p. 224].

\subsection{Overwhelming subjugation and collective self-censorship}

There are underlying principles why the confrontation of two ideologies has remained an unspoken phenomenon. Ideological despotism renders any official consensus - if not impossible - technically difficult and politically insecure. The embedded contention can be understood in two ways: First, it has been reflected on the physical characteristics of city's fabric; second, the contention has been incarnate in the character of city's notable citizens. Both Mashhad's civil and civic aspects are manifestos of ambiguity.

"The dominance of the Shiite clergy led some nationalist intellectuals to believe that the cultural hegemony of Shiite Islam must be challenged and replaced only by a new form of identity which emphasized Iran's pre-Islamic history and culture as well as the Persian language and its rich literary heritage" [7, p. 9]. "Only the heroism of a small group of Iranian poets and writers - the most prominent being the poet, Abol Qasem Ferdowsi (955-1010), the author of the epic poem, Shahnameh, who used a very limited number of Arabic words in the 60,000 couplets of his epic- had preserved the Iranian national identity" [7, p. 13]. Despite all negligence and attempts to marginalize it, Ferdowsi's tomb in Toos has remained popular.

M.R. Shajarian, the world well-known singer, is the personification of Mashhad's ambivalence. Being born in a religious family, he was never permitted to perform in his own city; whereas he gave concerts all around the world. His struggles against Islamic dogma, witnesses the city's two-folded civic character, yet he is one among millions counted as 98\% Muslim population [8].

How can these statistics reflect the true nature of Iran's diverse society, while there is no freedom in expressing other ideologies or belief systems? Being Muslim and in particular, being Shi'a is a taken for granted notion and imagining anything out of this confined constraint might be construed as a heresy.

\section{Urbanism as the proclaimer}

Architecture (the shrine), through its representational techniques, is quite capable of masking all ambiguities and sufferings under its dome, and present a counterfeited image of perfection and ideal. City's urbanism on the contrary, emancipated from a single authority, is the manifesto of uncertainty, ambiguity and tension. Two opposing socio-religious poles have reified into their spatial manifestations: the center and the axis.

The center, which essentially has a powerful religious theme, advocates centripetal, congested medieval growth, while the axis provides extensions and 
linear stretch. The former suggests radial, organic and informal, while the latter, signifies processional, regular and formal. The mutual influence of both has never turned toward extremes - it has remained moderate. In fact the perpetually stressed condition has played a progressive role in the sustainable growth of the city. Despite their hegemonic desire, none of the two had been able to maintain its dominance over the other for a long period. Even in the most abrupt situations, the city's evolution has been a balance between the two systems.

Mashhad's urban character is the eminent manifestation of its non-Islamic interests. With the exception of a limited number of religious and governmental edifices, the city presents, for the most part, diverse façade typologies whose design does not reflect motifs, ornaments or elements of Islamic architecture.

\subsection{The point of genesis, the origin}

The original nucleus comprises the Holy Shrine and the axis bisects its courtyard, is the epicenter of these two forces: the axis as the emblem of movement, progress and modernity; and the shrine, as the symbol of sincerity to the past, fixed values and polarization are the city's points of genesis. From the very beginning, the religious theme and all its related concepts have concentrated at the center, while all non-religious interests have been associated with the axial configuration. The relationship between the axis and the shrine is quite unconventional. The shrine is off-axis and the vanishing point is not the dome. This unique condition is rooted in the physical structure of the original garden which has been essentially a Persian garden with a determined axis.

There have been several configurations to the relationship of the axis and the object (which is known as Koshk), in Persian garden tradition [9]. Sometimes the object has been off axis so that the stream could have been continued through the garden. This has been reiterated in physical configuration of the palace which later became the shrine complex. The main courtyard, shaped around the intersection of the garden and the shrine's axis, interlocks with the main edifice embracing the dome. By being off axis in relation to shrine, the axis, passing through the courtyard - which will become the main street - provides more connectivity and interaction. The integrity of the void (the courtyard) and the object (The giant dome), well-established, substantiated by well-proportioned and locally adapted architectural elements of the thresholds and gateways, provided further annexations and conjointly introduced the whole complex as an integrated urban artefact into the city's fabric.

\subsection{From axis to street}

The city originally was located at the Kashafrood riverbank; however, because the river level was lower than the city itself, access to the water was quite arduous for the inhabitant. Thus the major portion of villages used the Ghanat (a type of spring with pure mineral water) as the primary source of edible water. The spring, originated at Sanabad, a village at the west side of Noghan, had more than thousand years of historic trace. The Toos governor's palace, the garden, 
and Haroon's tomb, have been situated at the same place which was less than one kilometer distance from the water's source [10].

With the evolution of the place into a pilgrim destination, the villages faced a water deficit crisis. Therefore at the beginning of 10th century, the province center shifted toward the Tabaran. At the very initial stages of the city's evolution, the trajectory of dwelling colonies accumulations stretched from Tabaran to the Shrine in a linear configuration (fig. 1). The pathway from Sanabad to the shrine, which was not only a pilgrim route, but an irrigation channel for the adjacent agricultural lands, inevitably occupied and Noghan and Sanabad lost their centrality in favor of the shrines hegemony and powerful influence. The city's physical growth and urban morphology soon surrendered to the center's influence and to the caravans' paths.

The connecting axis played a binary role: access and commerce. It reached to an apathetic rank in Shab 'Abbas era; the Bala Khiaban (upper street) and Pain Khiaban (down street) (fig. 2), widened and gradually city’s neighborhoods formed around initial origins such as Noghan, Sanabad, gates and main arteries [11]. From its embryonic status, common interests (economic benefits, social security and infrastructure availability) have been instrumental in the relative consistent consolidation of the axis into an active street. Collective megalomaniac intentions facilitated their beneficiary coexistence. The mutual influence of the two has brought about both social and urban equilibrium; by doing so, it has subverted a predicament to a merit.

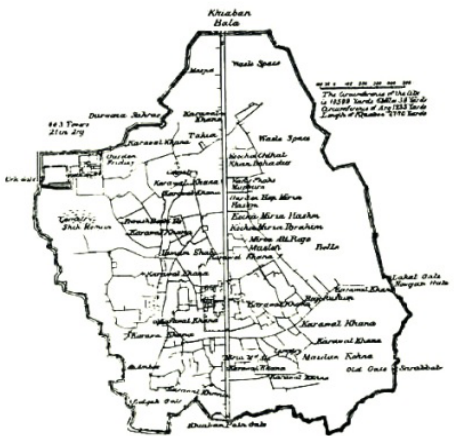

Figure 1: McGregor's map of Mashhad, 1875.

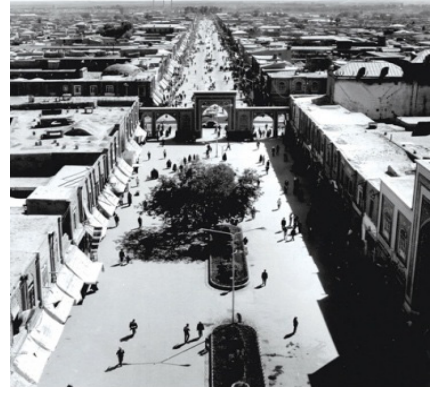

Figure 2: Pain Khiaban Musa alReza Sayyah’s archive.

\section{The geometry of struggle, the axis-center dialect}

The city basically is shaped around two figures: the shrine as both an icon and a place, and the main street that penetrates into the shrine's courtyard. Essentially, the city had always wrestled with the paradoxical theme of the axial configuration of street or radial spatial arrangement of the center. Occasionally, 
it had tried to yield to the lucidity of growth over the rings or to surrender to the power and tension of the axis.

As Braswell argues that authority in Islam is hierarchical [12], interestingly, the fabric generated by the Islamic-base center, consist of a succession radial repetitions, which is essentially hierarchical. In key historic moments for the shrine complex, all interlocking adjacent fabrics were demolished [13]. During the Pahlavi I, at the first half of the 20th century, Reza Khan cut through the fabric using a ring. Valian, Mashhad's mayor, offset the ring and demolished more of the old fabric at 1975, instead, replaced them with green spaces. At the beginning of the third millennium, the master plan consultant similarly superimposed a semi-circular street on the fabric [14]. The shrine complex however, is the combination of series of rectilinear courtyards which essentially have nothing to do with a circular configuration.

\subsection{The axis as promoter and means of extension}

The tomb chamber, as an object, frames and accommodates a very limited dimension - a body, proportionally, it is only capable of defining a limited space around it. By offsetting and reframing its void again and again - both horizontally and vertically - it can become bigger and bigger, however there is a limit to this repetition. The axis, on the contrary, has extended that limitation to far distances, not only visually but organizationally and spiritually as well.

The physical limitation of the center is its promising quality. It prevents quantitative and qualitative redundancies and similarities. Its limitation makes it unique, precious and adorable. The axis compensates the limitation. By definition, it is all about extension. Although there is a limitation to the physical influence of the shrine, the axis on the contrary, can generate an ordered, disciplined and rectilinear growth which is capable of extending far in distance; yet anarchy is latent in its vertical expansion. The shrine's configurational and perceptual restraints have been applied to the fabric which has been generated by it as well. At some point the radial, centripetal, and layered fabric loses its captivation toward the center, alienation and confusion resulting from their disassociation is manifest.

\subsection{The axis as organizer}

The axis, which has shaped the main street, has a two-fold character. First, its perfect linear geometry and horizontal order signifies the collective will to shape a coherent whole which characterizes the city's conciliatory attitude. Second, its occasional inharmonious dynamism implies an irreconcilable struggle between its ingredients. Therefore the three-dimensional disorder and the two dimensional order, are the evident characteristics of the city. Despite its thoughtfully deliberated zoning code, global market economy and Iran's political and economic upheavals have drastically afflicted the determinacy of its implementation. Therefore, the city, suffers architecturally from its chaotic three dimensional compositions; form urban point of view, this issue is not critically devastating. The axis, directing all attentions toward the center, has been an 
orientational device through which movements have been formulated in an orderly organized form. The axis adjusts itself by becoming wide and narrow enough so that its proportion and spatial perception remain relative to the shrine's proportion as well as rituals' spatial necessities.

Thus, the street has been more than a mere means of connection, but rather something in between - plaza and street. In Islamic culture, squares do not have the same meaning as their European counterparts. The center of any geometry should not be occupied by man - it belongs to Allah. Usually, water or green spaces are situated at the center of squares, courtyards, open spaces, etc. So street in Islamic cities is the surrogate for the congregational function of a plaza.

The Bala and Pain Khiaban had a threefold task: 1-Being the scene of urban theater, providing ample space to accommodate the rituals, 2-Housing the stream and trees along its length, and 3-Articulating the threshold needed for shops orchestrated along the street.

\subsection{A sophisticated articulation}

Even though the medieval fabric has irregularly developed around the shrine, the main axis has resisted the hegemony of the central organization. The units orchestrated along the up and down streets following the regulated geometry of the axis, had ordered divisions and compartitions. The complexity arises when the two systems meet; the inevitable articulation had to be justified. The desire of being closer to center, opportunistic land occupation and conformity to the radial pattern, collectively has been resulted in a congested, relatively irregular fabric, which exasperated the formulation of fabric's articulation (figs 3 and 4).

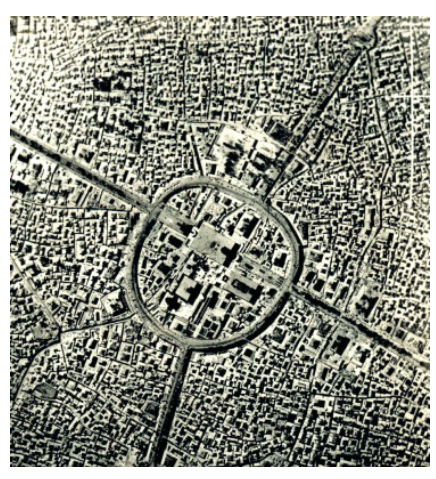

Figure 3: Aerial view, 1956 the surveying organization of Iran.

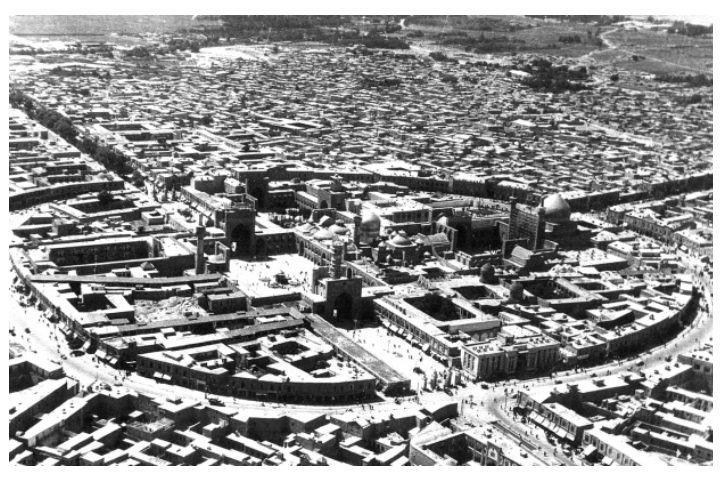

Figure 4: Aerial view of the center archive of Musa al- Reza Sayyah.

The idea of the courtyard as an un-roofed living space prioritized it to follow the perfected proportion of the indoor main spaces. The corridors and served 
spaces, however, were responsible in compromising with the adjacent proximities. Consequently, the radial clustering could not have taken place without complicated articulations. Adding to that, the diverse size of the blocks that was dependent upon the number of a collective families living simultaneously in a courtyard house, multiplied the complexity of the radial growth.

\subsection{The morphology of reconciliation}

To conform to the multiple level of necessities, i.e. social, cultural and economic necessities from one side and physical, spatial and organizational exigencies from the other, as well as adapting to a pilgrimage city's high demands, both urban morphology and architectural typology have yielded to a series of inevitable transformations during the city's evolution:

The traditional courtyard type, evolved to a more open configuration by reducing its massive and determined peripheral masses - a recurrent process in block typology's metamorphosis. Due to spatial restrictions, a courtyard block no longer could occupy a considerable width from a limited space of the street front; therefore the central courtyard began to shrink. It continued to the degree that it had no other choice but to be trans-positioned from the center to the front. The shift of a totally enclosed central space outward, had a bilateral positive effect to the block and to the urban space as well. The result was a narrow and deep block with a semi-public open space at the front/back. The emerging open space now served both the block and its immediate public space.

The perception of Mashhad's urban experiences is a consistent but not congested, in which streets are relatively wide and modern and the continuity of quasi-row house type has provided a harmoniously seamless fabric. While the block's periphery wall defines the immediate, pedestrian perception of a proportionate and reasonably enclosed urban space, the actual masses of the row buildings - set backed at one side of the street - forms a wider spatial configuration as the second urban scale. The position of semi-public open space is circumstantial to the climatic orientation. So that each individual block can receive an ample south direction exposure. The overall orientation, has usually tried to avoid East-West as the main direction.

The change in typology did not destabilize the city's conviction and long lasting tradition of generating formal public space: buildings collaborating in a symbiotic fashion to shape the street by making urban walls and remaining loyal to the memory of the city's collective will, in converting an open axis to a semienclosed urban space. Even with the semi-modern building type, the overall spatial configuration has dedicated to shape a coherent and consistent urban fabric. Despite all complexities, all variation and all permutations, the city's configuration can be easily formulated through the understanding of this theorem. 


\section{Shrine as a pretext and the compromised identity}

Mashhad pilgrimage has an ironic notoriety to many Iranians. It was an excuse to make a quasi-religious travel with a great deal of leisure, entertainment and recreation. In contrast to Hajj, the pilgrimage to Imam Reza shrine can be an absolutely appealing one, and it bears the least amount of burdensome and fastidious rites. It is a loose, fanciful version. For many pilgrims, shopping and visiting the Bazaar has been always more fascinating than visiting the shrine complex. Even no more than fifty years ago, people took photos with the photo of the shrine instead of the shrine itself, not only due to limited number of moving cameras but mainly because they preferred to spend time in fashionable streets with hundreds of attractive souvenir shops. With political solidarity, the city's collective will, consents to be mostly associated to its religious theme. This disguised insistence has enriched the economy of the city in a substantiated manner. The disguised identity has not been contested in favor of having an identity. Without a sincere subscription to the city's Islamic theme, an astute collective understanding of the merits of having an identity has generated a smooth relation between the opponents and ardent proponents. "In a party held in November 1973 at Hyatt Hotel, a hotel which had been funded by the Holy Shrine, the best Iranian and foreign cuisine, wines and liquors served; while Islam prohibits the consumption of alcoholic beverages” [15].

\subsection{Diluted identity as hyper identity}

There has been a perpetual oscillation between the emerging counterpoints and the center; yet the center has been, and perhaps will always remain the overarching theme - if not by belief, at least by political unanimity. This synthetic identity however, does not have the same meaning to the city's inhabitants as it has to the outside world. As the alternative or the existing counterpoint, reaches to its utmost limits, either physical or influential, usually two conditions happen. First, it becomes a bridge, a catalyst and basis for yet another one - close or far from that. Second, the emerging new pole independent of the former or liberated from the center, germinates from scratch elsewhere else. During the Pahlavi dynasty for instance, Arg Street had been the nonreligious multipurpose hub for the city, containing a dynamic range of entertaining, cultural and social activities [16]. The Koohsangi complex nevertheless, accommodated the royal palace and related leisure complexes, as an open landscape. These two have been counterpoints for the hegemony of the center. Similarly today, the city has accumulated a manifold number of competing and complementary places.

From its embryonic stage, the city was suffering from its pre-destined identity. The grieved spirit associated with martyrdom was in competition with the city's exhilarated will to flourish; one pushing backward and the other pulling forward have kept the city in a "delirious state”. Smart and opportunistic shifts, never got confined in a certain situation or predicament nor they did make the city a boring and tedious experience. The flexibility rooted in hesitancy and 
indeterminacy, provided the city with an ability of perpetual adjustment and transformations, which can be the promising quality of a sustainable habitat. If it became too small, it demolished its walls and expanded, if there was a limit to its horizontal expansion, it lifted vertically. If the center became redundant and ordinary, it reinvented the extraordinary so the extraordinary sooner or later again became ordinary and the center retrieved its extraordinariness.

\subsection{Endless candle: the perpetual city}

On June 20, 1994, the shrine was bombed [17]. Even at that very moment the access to the shrine complex was not blocked, but for a few hours. During the complicated process of excavating the entire shrine complex underground level again, the access did not shut off [18]. An un-predetermined arrival-time from long distant pilgrimage, along with the exigency of uninterrupted access for multitude of night prayers, that can be extended to Sahar (morning), are two fundamental reasons for such a unique characteristic. Thus, it is not a sedated city; nor is not a frozen one. It is all about going, moving and changing, it is perpetual. Nothing is bounded, even the time. The termination, the closing time and the limited movement, are alien concepts to the city.

\subsection{The farthest distance and walkable city}

Walking 1200 kilometers, barefoot from Isfahan to Mashhad to pay the ritual of pilgrimage has been a highly praised and laudable tradition [19]. The city accordingly outreached its hospitality far beyond its apparent physical boundaries. The caravansary as a type, for instance, was a place designed to be a solace to the thirsty pilgrims and travelers. To welcome the pilgrims and provide them with required services, the axis played a responsive task. It became the combination of dwelling and commerce. Consequently, the idea of mixed use is an authentically familiar concept to the city. Today, beside the city's modern shopping malls, still this retail tradition is quite pervasive. Almost every neighborhood has enough - and in many cases - an obsessively excessive number of retails, shops and services. This excessed overt agglomeration of commercial units and their unhealthy competition has had an impairing impact on their profitability and sustained income pattern.

\section{The ecology of competing interests, an affluent metropolis}

Mashhad inherently has been an affluent city. "Following Tehran, Mashhad has the second-largest market in the whole country with an employed population of more than 1.2 million persons" [21]. The reciprocity of the center and the axis has been instrumental in the formation of a robust economy. Their dependency and independency, allows adapting to different financial situations; i.e. it fluctuates upon haram's economy and the axis's one. Economic resilience, booming real estate values and the city's market diversity, have been the consequence of the balance between the two complementary systems - the bilateral economy. Economic crisis therefore, is an alien concept to Mashhad. 
While the center has been always the thematic strength, the axis occasionally, has extended its possibilities and introduced new points and potentials.

The axis is the representative of an independent, diverse and pluralistic business and investment economy, while the Shrine symbolises a subsidized, patronized and supported financial system - historically formulated around the idea of endowment. Over the course of its history, the city based on temporal necessities has gravitated toward one. The independent economy, started as an auxiliary system for the center, including services, amenities and shops to host the pilgrims, enriched by the well-practiced tradition of trade and commerce, intrinsic in the history of Toos, evolved to a more systematic and complex mechanism.

The independency of the street's economy enabled it to easily adapt, proliferate and permutate in response to emerging conditions. Consequently, more diverse forms of commercial activities and uses, evolved. From integrated single shops and small rooms connected to courtyard houses, it gradually get more complicated forms, such as huge mixed use complexes each containing hotels, shopping malls, cinemas, leisure and entertainment facilities.

\subsection{Two-fold endowments}

There are two classes of land ownership in Mashhad. The first group categorizes under Astane and Owgaf properties and the second is called Melki. As opposed to Melki - which are independent real estate properties - Astane and Owgaf are inherently donated, devoted or endowed to the Imam Reza. Even the private donations to the public or city itself, in one way or another, will be categorized as religious endowments and thus the Astane Ghods Organization will privilege their ownership. However the city benefited from two different sources of endowments, religious and non-religious. The single major influence in shaping city's sustainable character was Hossein Khan Malek. He had a conviction that Iranian's true prosperity and salvation is latent in sustaining the public's health and promoting their education [21]. Thus, he donated a tremendous amount of lands and money (1944 to 1955), not to promote and advocate religious institutions but to create hospitals, schools, museums, libraries and other public facilities such as parks and green spaces.

\subsubsection{Malek's endowments and a green metropolis}

Although Mashhad's geology comprises a diverse combination of mountains, river and plateau, the considerable allocation and integration of green and open spaces in the city's fabric is exemplary among many old cities. A tremendous amount of land endowments and horizontal distribution of them from one hand and the necessity of having streets wide enough to encompass a huge number of people all at once for the rituals have been the dominant underlying principles for the abundant dissemination of green and open spaces. These two however are subsidiary and incomparable to a single influence which the city as a green metropolis, could not have existed without his contributions. If the Imam Reza's martyrdom has shaped the city's monumental and religious character, the city's 
civic, public and green qualities are indebted to Malek's generous and insightful endowments, comprising vast areas of fantastic parks and landscapes.

\section{Conclusion}

After the 1979 Islamic revolution however, Mashhad exploded so that since 2001 it has become 30 times bigger than its extent inside its former wall with a 270 square kilometer area. Today it covers more than 300 square kilometers of land and bears more than 3 million of settled population and about 25 million pilgrims and travellers annually [22]. The city's current unfortunate status (especially during the last 15 years) resulting from absolute mismanagement, negligent and administrative corruption, will not be discussed here; but suffice to mention the country's recent political instability and subsequently its destabilized economy, along with the corrupt administrative and municipal systems collectively have resulted in an unfortunate urban destiny. A chaotic city skyscape resulting from illegitimate transgression in building height; inharmonious juxtaposition of different transect codes; unfavorable change of land use such as changing parks to shopping malls; proliferation of informal settlements at the city's periphery, etc. are the eminent predicaments the city is wrestling with. Despite all such miseries, the city's overall configuration has the potential to compensate and recover by the engagement of well-studied urban remedies.

Eventually, even with all these predicaments, Mashhad has maintained the promising qualities of its earlier sustainable urban condition, which distinguishes it as a model for contemporary emerging metropolises: From the social point of view, while in other locations of the Islam world, the tension between religious views has resulted in extreme and bloody confrontations, the city of Mashhad continues to provide favorable choices. Through a continuing process of reciprocity and reconciliation, the conflicts keep being subverted into symbiosis. On the one hand, abundant parks and open spaces, distanced from each other through axial configuration, and a multitude of mixed-used hotels and recreational and cultural centers - harmoniously scattered all along the city each supporting certain interests; on the other hand, those facilities have generated a unique dynamism between them all. Thus, Mashhad has not, and perhaps never will become a monolithic, polarized and stratified city. Still today, Mashhad unlike Gom for instance, where one theme has polarized the entire city, is not a bulk of mediocrity and manifestation of dogma. In this way, the city has transcended the tension, into an organization system, through which all groups can peacefully interact as a whole. From an economic perspective, the multitude and concatenation of retails and services along with the idea of a 24 hour city have been conducive to a safe street life and a walkable city. The urgency of providing non-stop, convenient and secured access and services, have been instrumental to the formation of a relatively modern infrastructure and public transport - a kind of civic sensitivity which has been essential to the city's sustainability. From an ecological vantage point, tremendous amount of reserved lands donated to the city, comprising huge parks, open spaces, reserved 
landscapes and so on, along with the city's astonishing wide streets and thoroughfares, supported by Mashhad's natural settings, have collectively performed as a sustained buffer to its explosive unsustainable growth.

\section{References}

[1] Derrida, Cf. J., "Interview with Jean-Louis Houdebine and Guy Scarpetta," in "Positions", The University of Chicago Press, p. 42, 1981

[2] Canby, R. S., Shah 'Abbas The Remaking of Iran', The British Museum Press, London, p. 186, 2009

[3] Kia, M., Persian nationalism and the campaign for language purification, Middle Eastern Studies, Frank Cass, London, 34(2), p. 13, 1998

[4] Kishwar, R., Sites of Pilgrimage and Objects of Devotion, Shah 'Abbas: The Remaking of Iran, ed. Canby, The British Museum Press, p. 99, 2009

[5] Jalali, G. R., Taqwim-e Khorassan, az Mashrootiyat ta Enqelab-e Eslami, Tehran: Markaz-e Asnad-e Enqelab-e Eslami, pp. 48-69, 1998

[6] Braswell, G. W. Jr., Civil Religion in Contemporary Iran, Journal of Church and State, 21(2), 1979

[7] Kia, M., Persian nationalism and the campaign for language purification, Middle Eastern Studies, Frank Cass, London, 34(2), 2006

[8] https://www.cia.gov/library/publications/the-world-factbook/geos/ir.html

[9] Pirnia, M. K., Iranian Gardens, Abadi journal, 4(17), pp. 67-74, 1994.

[10] Kazraji, A. D. M., Second Resāla, ed. and tr. Vladimir Minorsky, as AbuDulaf Mis 'ar ibn Muhalhil's Travels in Iran, Cairo, 1955. Translated into Persian by Tabatabai. Tehran, Zavvar bookstore, p. 84, 1975

[11] Kermanshahi, Sh., Sanabad from the village to the street, Shahrara Magazine, 1111, p. 11, Apr 25th 2013

[12] Braswell, G. W. Jr., Civil Religion in Contemporary Iran, Journal of Church and State, 21(2), p. 227, 1979

[13] Bill, J. A., The Eagle and the Lion: The Tragedy of American-Iranian Relations, the triumph of repression, p. 188, 1988

[14] Tash Consulting Engineers, Renovation and improving project of city center, Mashhad, Iran, 2000

[15] Kayhan International Newspaper ,Tehran, 10 Nov 1973

[16] Rezvani, A., In Search of Urban Identity Mashhad. Iran's Building and City Planning Department: Mashhad, Iran pp. 253-254, 2005

[17] Reeve, Simon, The New Jackals: Ramzi Yousef, Osama bin Laden, and the Future of Terrorism, London: Andre Deutsch Ltd, 1, pp. 63-67, 1999

[18] Manjusha, M., Shadow of the Silk Road, International Journal of Environmental Studies, 68(3), p. 402, 2011

[19] Monshi, E. B. /Savory, p. 752, 1978/R. Canby, S., Shah 'Abbas The Remaking of Iran, The British Museum Press, London, p. 191, 2009

[20] Ardam consultant, Iran, 8, p. 34, 1989

[21] http://www.malekmuseum.org/en/about/haj-hossein-malek.php

[22] Tash Consultant, Mashhad, Iran, pp. 11, 12, 2004 